\title{
The Enterprise in the Emerging Market Influenced by Coronavirus: Experience From IHG
}

\author{
Jiayi Gong \\ Ningbo XiaoShi High School, Ningbo, Zhejiang Province, China \\ Corresponding author's e-mail: Vivian.wang@cas-harbour.org
}

\begin{abstract}
During the coronavirus, the economy is experiencing the downtown of the business cycle, which is also the recession in the market. The GDP grows negatively and both business producers and customers do not have the confidence about the future in various industries. IHG, one of the giants of the travel and hospitality industry, have to deal with the finical problems brought by the coronavirus. Consequently, the author decided to take "The Enterprise in the Emerging Market influenced by Coronavirus: Experience from IHG" as the topic to discuss the influences of recession for the hospitality industry. During the discussion, the author will discuss the positive and negative influences of IHG from various aspects according to the data and charts of the online survey. What is more, from an objective point of view, the author will be able to analyze which methods intercontinental hotel can utilize to solve diversity of problems. All in all, according to different types of explantations and examples, it is safe for me to conclude that the recession has had an unimaginable influence on tourism. As one of the giants of the hospitality industry, IHG is not immune. Falling tourist numbers and rising cost of the production have put large pressure on the IHG.
\end{abstract}

Keywords: The Intercontinental Hotel Group, unemployment, economic recession, coronavirus

\section{INTRODUCTION}

The Intercontinental Hotel Group which is also called IHG was founded in 1777. It is the world's largest and most widely distributed professional hotel management group. It develops different types of brands such as intercontinental, Crowne Plaza, Holiday Inn and other internationally wellknown hotel brands. What is more, IHG has more than 60 years of international hotel management experience. At the same time, IHG also has the largest number of rooms in the world (up to 650,000 rooms), the widest range of transnational operations, and has taken over the largest number of hotels in China. The managers in IHG developed "Five Winning Ways" as their own unique corporate culture to achieve their vision, which is to be an outstanding hotel that guests will love. "Five Winning Ways" includes doing the right things, showing we care, aiming higher and celebrating difference as well as working together. Through these five corporate cultures, company managers develop various leadership styles and strategic decisions that gradually enhance their competitiveness and help them expand their economies of scale.

\section{INFLUENCES CAUSED BY CORONAVIRUS}

However, during the period of coronavirus in 2020, companies in the hotel industry have no choice but to overcome unpredictable challenges because of the economic recession. The recession occurs during the downtown of the business cycle, when the GDP grows negatively. In the first quarter of 2020 , as shown in the figure $1,85.3 \%$ of hotel merchants reported a significant drop in business volume during the epidemic, while only $1.4 \%$ of respondents reported an increase in business volume [1]. Under the impact of the epidemic, hotel business is facing difficulties in operation and the pressure on survival increases sharply. What is more, $69.3 \%$ of the hotel merchants surveyed said that the most significant difficulty they faced in the first quarter was the challenge of cash flow and the huge pressure of expenditure [1]. The increase of cash outflow and the decrease of cash inflow results in merchants facing very large financial pressure. Business stagnation is also a major challenge for merchants, with $68.6 \%$ and $64.0 \%$ respectively saying that the main difficulties are business stagnation and market demand change [1].

\begin{tabular}{|l|c|}
\hline Do not plan to travel & $25.8 \%$ \\
\hline $\begin{array}{l}\text { Do not travel until the } \\
\text { epidemic is over }\end{array}$ & $24.0 \%$ \\
\hline $\begin{array}{l}\text { Have plans to go on a trip } \\
\text { but have not made any } \\
\text { plans yet }\end{array}$ & $21.1 \%$ \\
\hline $\begin{array}{l}\text { Have plans to travel and } \\
\text { have made plans }\end{array}$ & $17.9 \%$ \\
\hline Have been on a trip & $11.2 \%$ \\
\hline
\end{tabular}

Figure1 Example of Travel Intentions of Chinese Netizens in the First Quarter of 2020 
According to the research data above, it is obviously that nearly half of people do not plan to travel to China. The sudden influence of the epidemic has not only led to a change in Chinese travel habits and attitudes, but also to decline sales in the hotel industry at a speed of rocket.

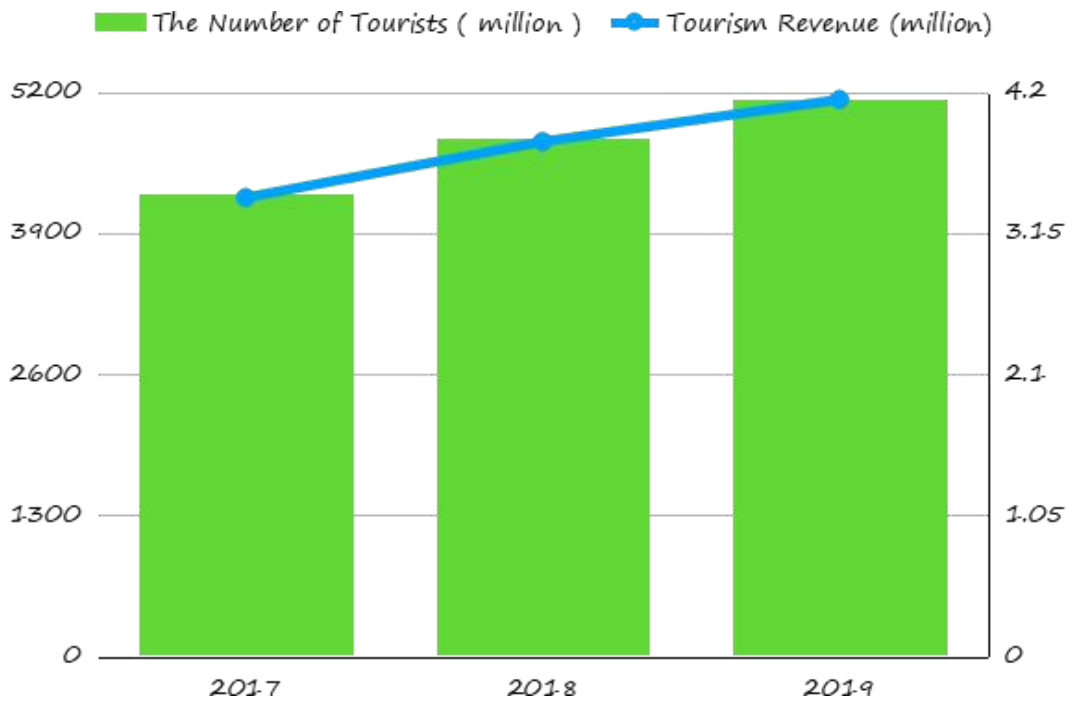

Figure2 Example of Spring Festival Tourism Market from 2017 to 2019.

Taking the 2019 Spring Festival holiday in China as an example, as shown in the figure 2, communication operators and online travel service providers in different regions, the total number of tourist visitors nationwide reached 415 million, up 7.6\% year-on-year [2]. Tourism revenue reached

513.9 billion yuan, up $8.2 \%$ year-on-year, and the cultural and tourism markets flourished in an orderly way [2]. However, during the Spring Festival in 2020, the golden week of Spring Festival tourism was completely banned under the influence of the epidemic [2]. According to the consumption estimate of the Spring Festival in 2019, the loss of Spring Festival in 2020 exceeded 500 billion yuan [2]. The coronavirus had very huge influence on IHG and it is significant for managers in IHG to come up with several methods to solve these problems.

\section{POSITIVE CONSEQUENCES}

IHG is also aware of the importance of health quality. Due to environmental and health concerns, all iHG hotels will eliminate micro cleaners, becoming the first hotel brand in the world to do so. UK owners of Holiday Inn and Crown Plaza have pledged to remove small plastic bottles from their 843,000 rooms by 2021 [5]. Last year, IHG also said it would stop using plastic straws by the end of 2019. Mr. Barr expressed that the next most essential things for hotels to deal with were the plastic plates and cutlery for breakfast. In an effort to improve hotel health more efficiently, the company is also working with artificial intelligence company Winnow on a pilot project to monitor garbage in some of its hotel breakfast buffets [5].
Intercontinental has pledged to reduce its carbon footprint per room by $6 \%$ by next year [5]. High-end resort brand Six Senses, for example, says its supply chain will be plastic-free by 2022 [5]. This change at IHG during the coronavirus is beneficial because it improves its corporate image through ethical and social responsibility. Media around the world will report on iHG's ethical business practices, which will help enhance its image and reputation. In addition, intercontinental hotels can increase customer loyalty. Customers are more likely to be loyal to businesses that do not engage in unethical behavior. They will be aware that IHG made this decision to protect the environment and the safety of its customers.

\section{NEGATIVE CONSEQUENCES}

\subsection{Increase in Unemployment}

However, IHG does not achieve the objective of reducing the unemployment. The unemployment indicates that people who at working age or in the labour force want to have jobs but do not have the jobs. During the coronavirus, the economy grows negatively and people gradually lose the consumer confidence and business confidence because of the low GDP. To prevent the novel coronavirus from further spreading, IHG has no choice but to close a portion of its hotels. As of April 27, IHG had temporarily closed 10 percent of its hotels in the United States and 50 percent of its hotels in Europe, the Middle East, Africa and Asia (excluding China) [3]. The closure of the hotel also results 
in some hotel staff losing their jobs, such as cleaners since IHG cannot provide large amounts of salaries for their employees without making a profit from the industry. Consequently, the percentage of unemployment in the market increases to a large extent. For instance, IHG has started consulting with its hotel staff in Edinburgh and Glasgow on job cuts [4]. According to the survey, most employees started taking vacation in March. Managers in IHG indicated that this was a very difficult and special time for their particular industry, and while they are doing their best to prevent staff being made redundant, they have had to resize their hotel team and lay off some staff [4].

\subsection{Decrease in RevPAR}

Revenue per available room is also known as revenue per available room. It refers to the average real income per available room. In 2020, due to COVID-19, the performance index of the hotel was significantly reduced. Global average RevPAR decreased $24.9 \%$ in the first quarter and $55 \%$ in March. In its first quarterly earnings report, IHG released monthly revenue data for available room RevPAR [3]. Edgecliffe, one of iHG's managers, expects April available revenues to fall by around $80 \%$ compared with April 2019 [3]. In addition, 65\% of IHG's brands are high quality of hotels, which have proved better able to overcome difficulties in other crises. For example, in March 2020, RevPAR was about 3\% higher than other international brands around the world [3]. Mr Barr, one of iHG's leaders, points out that RevPAR fell by $55 \%$ in the British and $70 \%$ in Germany in March, as major trade shows were canceled [3]. At the same time, in Europe and Africa, RevPAR decreased by about 90 percent in March [3]. " We have been running our business conservatively and most of our money is invested in maturing bonds, with the first $\$ 400 \mathrm{~m}$ due in 2022, " [3] Edgecliffe said, "We have at least 18 months to maneuver. [3]" As of May, IHG shares were down 31.8 percent from a year earlier at 35.62 pounds (\$44.02) [3]. The Baird/STR hotel index fell 44.72 percent over the same period [3].

\section{POSSIBLE SOLUTIONS TO THE PROBLEMS}

First of all, governments can choose to provide the subsidy to IHG so that there is an increase in the cash-flow for the enterprise. The subsidy is the money provided by the government to the companies in order to stimulus their efficiency of production. Appropriate use of fiscal subsidies in a certain period of time is beneficial to the coordination of political, economic and social conflicts of interest, which plays a positive role in stabilizing prices, protecting the interests of producers, operators and consumers, maintaining social stability, and promoting the development of planned commodity economy. From the government's point of view, payment to the enterprise is free; from the recipients' perspective, it means an increase in real income and an improvement in economic conditions. Fiscal subsidy is related to the change of relative price, and it has the effect of changing the structure of resource allocation, supply and demand.

What is more, governments are also allowed to decrease the corporate tax to the enterprise. Provided that IHG can only give governments less tax revenue, they will have less fiscal pressure and decrease in the budget deficit. Reducing government taxes can also increase total market demand, because reducing personal income tax undoubtedly increases personal disposable income, thus stimulating consumption. Reducing corporate income tax will increase corporate investment; increasing government spending and reducing taxes will increase national income and thus stimulate economic development during the epidemic.

The government can choose one of these ways to provide funds to the enterprises, or else the government will also suffer a financial crisis.

\section{CONCLUSION}

The recession has dealt a deadly blow to tourism. Although IHG has a significant position in the hospitality industry, it has not been immune to the impact of the economic downturn. The number of visitors is falling and the rising cost of wages and day-to-day running of hotels is putting pressure on the continent.

\section{ACKNOWLEDGMENT}

Before writing the thesis, I often communicated with the business teacher in my school about the idea of IHG. I will collect different data and contact different cases to analyze and evaluate IHG. Mr.Momeni, who is my business teacher in my school, also taught me how to write reference accurately in this process. At the beginning of writing the paper, I often communicate with my advisor, because I do not know how to build a framework and structure for the paper and I am confused what kind of content should be included in this paper. After I provided my abstract to the tutor, she gave me some useful advice, and I also realized that I needed to change my focus on topic. Additionally, after I resubmitted the last draft, the teacher told me the formal chart and reflection format, which made me realize that the real paper format was very rigorous. In the process of writing this paper, I think I have learned how to obtain materials correctly, follow teachers' opinions reasonably, and regulate typesetting. 


\section{REFERENCES}

[1] AiMei Website. OTA Platform represents Four New Normals in the "epidemic fighting" important support marke. Published on 2020/7/6. Access from: http://finance.sina.com.cn/stock/relnews/cn/2020-0706/doc-iircuyvk2291259.shtml, access on 2020/7/7

[2] Baijiahao. The Tourism Industry is the third in a Series of Industry Analysis that will be greatly affected by the Epidemic in 2020. Published on 2020/3/19. Access from:

https://baijiahao.baidu.com/s?id=1661554755052155743 $\& w f r=s p i d e r \&$ for $=p c$, access on 2020/7/5.

[3] MDDD. Reflections on recovery in the postepidemic Era of Intercontinental Hotels Group.

Published on 2020/5/8. Access from: https://www.jianshu.com/p/8dcdfe1472b7, access on 2020/7/5

[4] Coronavirus: Jobs under threat at five Scottish hotel. Published on 2020/6/4. Access from: https://www.bbc.com/news/uk-scotland-scotlandbusiness-52923731, access on 2020/7/20

[5] BBC. Mini toiletries to be removed from Holiday Inn owner's hotels, published on 30 July 2019. Access from (https://www.bbc.com/news/business-49163456 ) , access in 2020/7/18 